\title{
Evidence that polymorphonuclear neutrophils infiltrate into the developing corpus luteum and promote angiogenesis with interleukin-8 in the cow
}

Sineenard Jiemtaweeboon ${ }^{1}$, Koumei Shirasuna ${ }^{1 *}$, Akane Nitta ${ }^{1}$, Ayumi Kobayashi', Hans-Joachim Schuberth², Takashi Shimizu ${ }^{1}$ and Akio Miyamoto ${ }^{1}$

\begin{abstract}
Background: After ovulation in the cow, the corpus luteum (CL) rapidly develops within a few days with angiogenesis and progesterone production. $\mathrm{CL}$ formation resembles an inflammatory response due to the influx of immune cells. Neutrophils play a role in host defense and inflammation, and secrete chemoattractants to stimulate angiogenesis. We therefore hypothesized that neutrophils infiltrate in the developing $\mathrm{CL}$ from just after ovulation and may play a role in angiogenesis of the $\mathrm{CL}$.

Methods and Results: Polymorphonuclear neutrophils (PMN) were detected in $\mathrm{CL}$ tissue by Pas-staining, and interleukin-8 (IL-8, a neutrophil-specific chemoattractant) was measured in supernatant of the CL tissue culture: considerable amounts of PMNs and the high level of IL-8 were observed during the early luteal phase (days 1-4 of the estrous cycle). PMNs and IL-8 were low levels in the mid and late luteal phases, but IL-8 was increased during luteal regression. The PMN migration in vitro was stimulated by the supernatant from the early $\mathrm{CL}$ but not from the mid $C L$, and this activity was inhibited by neutralizing with an anti-IL-8 antibody, indicating the major role of IL-8 in inducing active PMN migration in the early CL. Moreover, IL-8 stimulated proliferation of CL-derived endothelial cells (LECs), and both the supernatant of activated PMNs and IL-8 stimulated formation of capillary-like structures of LECS.
\end{abstract}

Conclusion: PMNs migrate into the early $C L$ partially due to its major chemoattractant IL-8 produced at high levels in the $\mathrm{CL}$, and PMNs is a potential regulator of angiogenesis together with $\mathrm{IL}-8$ in developing $\mathrm{CL}$ in the cow.

\section{Background}

The corpus luteum (CL) is a unique endocrine organ that develops from the ovulated follicle during the sexual cycle. The main function of the CL is to secrete a large amount of progesterone $(\mathrm{P})$, which is essential for establishment and maintenance of pregnancy. After ovulation, inadequate function of the $\mathrm{CL}$ is one of major causes of infertility in cows [1]. Angiogenesis is fundamental to the normal development of the CL in many species. One of the major angiogenic factors, basic fibroblast growth factor (FGF2), is generally involved in cell

\footnotetext{
* Correspondence: shirasuna@obihiro.ac.jp

${ }^{1}$ Graduate School of Animal and Food Hygiene, Obihiro University of

Agriculture and Veterinary Medicine, Obihiro 080-8555, Japan

Full list of author information is available at the end of the article
}

growth, differentiation, transformation and angiogenesis. Gospodarowizc et al. [2] have been shown that FGF2 is produced in the bovine CL and stimulates neovascularization and proliferation of a wide variety of cells, such as vascular smooth muscle cells, granulosa cells and endothelial cells. Additionally, vascular endothelial growth factor A (VEGFA, mainly localized in the cytoplasm of luteal cells) also is major player for angiogenesis and plays a fundamental role in maintenance of the vasculature in the $C L$ when it is no longer undergoing active angiogenesis [3].

Cytokines and chemokines, such as prostaglandins (PGs) [4], tumor necrosis factor $\alpha$ (TNF $\alpha$ ) [5], interleukin (IL)-1 [6] and IL-8 [7,8] are found in high concentrations in the follicular fluid in the pre-ovulatory phase. 
Consequently, high numbers of neutrophils and macrophages infiltrate in the pre-ovulatory follicle at the time of ovulation [9]. Indeed, neutrophil depletion by administration of a monoclonal antibody against neutrophils reduced the ovulation rate in rats, indicating a critical role for neutrophils in ovulation [10]. After ovulation, a multitude of leukocytes, such as macrophages and eosinophils are located in the luteinizing theca area in the developing CL [11-13]. This series of phenomena from ovulation to luteal development involves bleeding, immune cell infiltration, tissue remodeling and angiogenesis, implying that the development of the CL following ovulation is a kind of physiological injury with an inflammatory response. In general, polymorphonuclear neutrophils (PMN) are the first cells recruited to inflammatory sites, providing cytokines and proteolytic enzymes. Moreover, PMNs secrete VEGFA [14] and induce the sprouting of capillary-like structures of endothelial cells in vitro [15], suggesting that PMNs have a potential role, not only in phagocytosis, but also in the regulation of angiogenesis.

IL- 8 is a small protein $(8.4 \mathrm{kDa})$ and produced by macrophages, endothelial cells and neutrophils $[15,16]$. IL- 8 has been shown to be a neutrophil-specific chemoattractant [16], and IL-8 is involved in angiogenesis, cell proliferation, and apoptosis $[16,17]$. In the ovary, IL8 is detected in theca, granulosa, granulosa-lutein, and vascular endothelial cells in humans $[18,19]$ and rabbits [20]. Goto et al, [21] observed that IL-8 injection increased follicular growth and capillary vessel densities around the follicles in rats. Furthermore, treatment of anti-IL-8 antibody inhibited the hCG-induced ovulation rate [22], suggesting that IL-8 participates in the regulation of ovarian function to induce ovulation. However, no evidence has been shown regarding the role of neutrophils and IL-8 in the life span of the bovine CL.

We hypothesized that PMNs infiltrate in the developing CL from just after ovulation and may play a role in angiogenesis of the CL. Therefore, in the present study, we investigated the localization of PMNs and their chemoattractant, IL-8, in the bovine CL during the estrous cycle and effects of PMNs and IL-8 on the function of luteal endothelial cells in vitro.

\section{Methods}

\section{Experiment 1: the estrous cycle}

Ovaries were collected from a local slaughterhouse and CLs were classified according to stage of the estrous cycle by macroscopic observation (color and size of the CL) and weigh of the CL as described previously [23]. The stages of the estrous cycle were estimated as follows: early, (i) days 1-2, (ii) days 3-4, (iii) days 5-7; mid, days 8-12; late, days 13-16; and luteal regression, days 18 or greater of the estrous cycle $(n=4-5$ in each stage). To use immunohistochemical analysis, CL samples were fixed with $10 \%$ formaldehyde for $24 \mathrm{~h}$, and embedded in paraffin wax according to the standard of histological technique. In addition, CL was minced and approximately $0.1 \mathrm{~g}$ of luteal tissues was placed into a 1.5-ml microcentrifuge tube with $400 \mu \mathrm{l}$ of TRIzol reagent (Gibco BRL, Gaithersburg, MD) and stored at $-80^{\circ} \mathrm{C}$ for further analyzed. Also, to detect IL-8 concentration from the CL, the early- (days 3-4), mid-, late and regressing phase of CLs were cut into cubes (length, 4 $\mathrm{mm}$; side, $2 \mathrm{~mm}$; thickness, $2 \mathrm{~mm} ; \mathrm{n}=4-5$ in each stage). The CL tissues were washed in DMEM/F-12 (Invitrogen Corporation, Tokyo, Japan) with $0.1 \%$ fetal bovine serum (FBS; Invitrogen Corporation) for $15 \mathrm{~min}$. Subsequently, the CL tissues were rinsed with phosphate buffered saline (PBS) to eliminate the effect of the FBS and transferred to serum-free DMEM/F-12 medium medium containing $0.1 \%$ BSA, $0.1 \%$ gentamicin solution (50 mg/L, SIGMA, St. Louis, MO, USA), and $1 \%$ amphotericin B solution (2.5 mg/L, SIGMA). CL tissue was set in a 48 -well plate (1 tissue/well). Incubation was carried out for $8 \mathrm{~h}$ at $37^{\circ} \mathrm{C}$. Then, supernatant of the $\mathrm{CL}$ tissue was harvested, and IL- 8 within the supernatant was measured using an ELISA kit for bovine IL-8 (USCN Life Science Inc., Wuhan, China). The standard curve for IL-8 ranged from 15.6 to $1000 \mathrm{pg} / \mathrm{ml}$.

\section{Luteal cells (LCS) and luteal endothelial cells (LECS) culture}

The CLs of the mid luteal phase were collected at local slaughterhouse, and dispersed using collagenase IV (SIGMA). The luteal stages were classified as mid (days 8-12 of the estrous cycle) by macroscopic observation of the ovary as described previously [24]. LCs was isolated from the bovine mid CL (Days 8-12 of the estrous cycle) using magnetic tosylactivated beads coating with BS-1 lectin (binds glycoproteins on the bovine endothelial cells), BS-1 negative cells were assessed as enriched LCs (including smooth muscle cells and pericytes) as described previously [25]. Before experiment, we confirmed the mRNA expression of steroidogenic acute regulatory protein and endothelial nitric oxide synthase as a maker of LCs in BS-1 negative cells and a maker of LECs in BS-1 positive cells, respectively (data not shown). LCs were cultured in DMEM/F-12 medium containing 5\% FBS, 2.2\% NaHCO3, gentamicin solution, and amphotericin B solution. Cytokeratin- negative LECs isolated from the CLs of the cows during the midluteal phase were used as described previously [26]. LECs were grown on plates pre-coated with $1 \%$ Vitrogen in DMEM/F-12 medium containing 5\% FBS, $2.2 \%$ $\mathrm{NaHCO} 3$, gentamicin, and amphotericin B solution. All experiments in the present study were carried out on LECs from passages 5 to 8 . For analysis of mRNA expression, LCs and LECs were cultured for $24 \mathrm{~h}$ at $37^{\circ}$ $\mathrm{C}$, then placed into a $1.5-\mathrm{mL}$ microcentrifuge tube with 
$400 \mu \mathrm{L}$ of TRIzol reagent and stored at $-80^{\circ} \mathrm{C}$ until analysis.

\section{Experiment 2: PMN migration capacity of early- and mid- phase luteal tissue \\ PMN isolation}

Whole blood $(20 \mathrm{ml})$ was mixed with an equal volume of PBS. The suspension was layered onto Ficoll-Paque solution (Lymphoprep, AXIS-SHIELD, Norway) and then centrifuged at $1000 \times g$ at $10^{\circ} \mathrm{C}$ for $30 \mathrm{~min}$ as described previous study $[27,28]$. The plasma and buffy coat (population of mononuclear cells) were discarded. Contaminating red blood cells were washed in hypotonic distilled water for approximately $10 \mathrm{sec}$. Isotonicity was restored by the addition of twice concentrated-PBS. PMNs were centrifuged at $500 \times g$ at $10^{\circ} \mathrm{C}$ for $10 \mathrm{~min}$ and then the cell pellet was washed twice with PBS. Isolated PMNs were resuspended at a concentration of $2 \times 10^{6}$ cells $/ \mathrm{ml}$ in RPMI 1640 (Invitrogen) with 0.1\% FBS. PMNs viability was $99 \%$ as assessed by the Trypan blue staining. To check the purity of PMNs before using for the experiment, the purity of PMNs was > 95\% and these cells resulted in nearly pure granulocyte populations as determined by flow cytometric evaluation (Beckman Coulter, Inc., CA, UAS) [27,28]. Additionally, we observed giemsa-stained PMNs by microscope, these cells were clear granule and segmented nuclear. Although peripheral granulocytes include neutrophils, eosinophils and basophils in generally, the purity of neutrophils (2-5 lobes of nuclear and finely-granular) was $>95 \%$ in these PMNs by microscope observation in the present study since character was different between neutrophils and eosinophils (double nuclear and coarsely-granular).

\section{Migration assay by culture medium and detection of IL-8}

Supernatants of the early- (days 3-4) and mid- (days 812) phase CLs were used ( $\mathrm{n}=4$ in each stage) as described above. PMN chemotaxis was evaluated using a 10-well microchemotaxis chamber (Neuro Probe, Inc., Gaithersburg, MD, USA). Test solutions in the bottom chamber were separated from leukocytes in the upper chamber by an $8-\mu \mathrm{m}$ pore-sized filter (Neuro Probe, Inc.). The following solutions $(300 \mu \mathrm{L})$ were pipetted into the bottom chamber: (i) medium alone, (ii) supernatant derived from the early- or mid-phase CL tissue culture, and (iii) recombinant bovine IL-8 $(50 \mathrm{ng} / \mathrm{ml})$ as a positive control. After instrument assembly, PMNs were added to the upper chamber $\left(250 \mu \mathrm{l} /\right.$ well; $2 \times 10^{6}$ cells $/ \mathrm{ml}$ ). After a $3 \mathrm{~h}$ incubation at $37^{\circ} \mathrm{C}$ in $5 \% \mathrm{CO}_{2}$, migrated cells in the bottom chamber were counted using a light microscope.

\section{Inhibition of IL-8 function in PMN migration in early-phase CL supernatan}

To investigate the possible role of IL-8 as a neutrophilspecific chemoattractant in early-phase CL tissue culture supernatant, we inhibited IL-8 function using anti-IL-8 monoclonal antibody reacted with bovine IL-8 (Ab; MAB1044, Millipore Corporation, Australia) and then performed a transmigration assay. The supernatant of each CL was incubated with anti-IL-8 Ab $(30 \mu \mathrm{g} / \mathrm{ml})$ or same dose of normal IgG as control at $37^{\circ} \mathrm{C}$ for $1 \mathrm{~h}$ in duplicates ( $\mathrm{n}=4$ in each group). Following incubation, media were analyzed for PMN migration as described above. The following solutions $(300 \mu \mathrm{l})$ were pipetted to the bottom chamber: (i) medium alone, (ii) supernatant derived from the early CL culture with or without IL-8 Ab pre-treatment, and (iii) recombinant IL-8 (50 ng/ml) as a positive control. After instrument assembly, PMNs were added to the upper chamber $\left(250 \mu \mathrm{l} /\right.$ well; $2 \times 10^{6}$ cells $/ \mathrm{ml}$ ). After incubation at $37^{\circ} \mathrm{C}$ in $5 \% \mathrm{CO}_{2}$ for $3 \mathrm{~h}$, migrated cells in the bottom chamber were counted using a light microscope.

\section{Experiment 3: effect of PMNs and IL-8 on live cell number of luteal endothelial cells and capillary tube formation Live cell number of luteal endothelial cells}

LECs as described above was used in the experiment. These cells were grown in DMEM/F-12 containing 5\% FBS $\left(1 \times 10^{5}\right.$ cells/well in 24 -well plates $)$ for $24 \mathrm{~h}$ at $37^{\circ}$ C. Then, LECs were rinsed with PBS twice, and fresh medium was replaced with medium containing IL-8 (1, 10 and $100 \mathrm{ng} / \mathrm{ml}$ ) for $48 \mathrm{~h}$ in DMEM/F-12 medium containing $0.1 \%$ FBS. Then, cells were trypsinization and the number of LECs was counted by light microscope as live cell number of LEC without dead cells staining with Trypan blue.

\section{Capillary tube formation on matrigel of luteal endothelial cells}

Capillary-like tube formation of LECs was evaluated as previously described [29]. Briefly, 48-well plate was coated with $200 \mu \mathrm{l} /$ well of BD matrigelTM basement membrane (BD biosciences, Bedford, MA, USA) at $4^{\circ} \mathrm{C}$, which was then allowed to polymerize at $37^{\circ} \mathrm{C}$ for at least $1 \mathrm{~h}$. LECs $\left(2 \times 10^{4}\right.$ cells/well $)$ were cultured in a final volume of $0.5 \mathrm{ml}$ in LEC culture medium containing IL-8 $(1,10$ and $100 \mathrm{ng} / \mathrm{ml})$ or the supernatants from PMNs ( $n=4$ in each group). To obtain the supernatant from PMNs, PMNs from the early luteal phase were cultured in 48 -well plates $\left(1 \times 10^{6}\right.$ cells/well $)$ in the presence of $\mathrm{N}$-formyl-methionyl-leucyl-phenylalanine (fMLP, 10 and $100 \mathrm{nM}$ ) or without fMLP as control for $1 \mathrm{~h}$ at $37^{\circ} \mathrm{C}$ as previously described [15]. After stimulation of PMNs with fMLP, supernatant of activated PMNs were harvested and used for the assessment of capillary tube formation ( $\mathrm{n}=4$ in each group). After $8 \mathrm{~h}$ incubation, tube formation was examined visually in three random images imported at a magnification of $100 \times$ by inverted microscope, and the length and the area of tubular structure in each image $(1 \times 1 \mathrm{~mm})$ 
were analyzed using Adobe photoshop CS3 software. Data are shown as mean \pm SEM.

Histology and PMNs counting In experiment 1, PMNs were detected using paraffin sections stained with periodic acid - Schiff's (PAS) reagent for $10 \mathrm{~min}$, and then counterstained with hematoxylin (Certistain, Merck, Germany) [30]. This PAS stain was used on each tissue block, and 5 fields per section were examined at $\times 400$ magnification. Although red blood cells and other immune cells, such as macrophages are stained in the CL tissue, therefore in addition to positive cells by PAS staining, we checked the shape of nuclear of cells and assessed segmented granulocytes as PMNs. Thus, we could distinguish PMNs especially neutrophils from other PAS stained positive cells, such as red blood cells and macrophages. Quantification of the number of PMNs was performed independently by 3 observers. The numbers of PMNs/0.04 $\mathrm{mm}^{2}(200 \times 200 \mu \mathrm{m})$ were independently counted under a light microscope. Intraand inter-observer differences were $<10 \%$. Data are shown as mean \pm SEM.

\section{RNA isolation and real-time PCR}

Total RNA was extracted following the protocol of Chomczynski and Sacchi using TRIzol reagent [31] as in our previous study [32]. The extracted total RNA was stored in RNA storage solution (Ambion, Texas, USA) at $-80^{\circ} \mathrm{C}$ until use for cDNA production. RNA samples were treated with DNase using the RQ1 RNase-Free DNase kit (Promega. Co., Madison, WI, USA) as in our previous study [32]. The synthesized cDNA was stored at $-30^{\circ} \mathrm{C}$.

PCRs were quantified using a LightCycler (Roche Diagnostics, Indianapolis, IN, USA) and a commercial kit (LightCycler FastStart DNA Master SYBR Green I, Roche Diagnostics) as describe previously [32]. The quantification of mRNA expression was performed using Light Cycler Software (Version 3.5; Roche
Diagnostics). The primers used for real-time PCR were as follows: IL-8 (NM_173925, 170 bp), forward, 5CCTCTTGTTCAATATGACTTCCA-3 and reverse, 5GGCCCACTCTCAATAACTCTC-3; GAPDH (NM_00 1034034, $160 \mathrm{bp}$ ), forward, 5-CTCTCAAGGGCATTC TAGGC-3and reverse, 5-TGACAAAGTGGTCGTT GAGG-3. The amplification program consisted of 15 min activation at $95^{\circ} \mathrm{C}$ followed by 40 cycles of PCR steps (15 sec denaturation at $94^{\circ} \mathrm{C}, 30 \mathrm{sec}$ annealing at $58^{\circ} \mathrm{C}$ and a $20 \mathrm{sec}$ extension at $72^{\circ} \mathrm{C}$ ). The quantification of mRNA expression was done using Light Cycler Software (Version 3.5; Roche). The values were normalized using GAPDH as the internal standard. Following electrophoresis of the PCR, the target band was cut out, PCR amplicons were sequenced in both 5' and 3' orientation to confirm the PCR amplicons as IL- 8 and GAPDH using an Applied Biosystems $3730 \times 1$ DNA Analyzer (Applied Biosystems, Foster City CA, USA).

\section{Statistical analysis}

All data are presented as means \pm SEM. The statistical significance of differences about PMNs number, IL-8 expression of both mRNA and protein, PMN migration levels, LEC proliferation and LEC matrigel assay was assessed by one-way ANOVA followed by Bonferroni's multiple comparison test. Probabilities less than 5\% (P< $0.05)$ were considered significant.

\section{Results}

Quantification of PMNs and IL-8 mRNA expression and protein in the $\mathrm{CL}$ during the estrous cycle

The number of PMNs, IL-8 mRNA and protein during the estrous cycle are shown in Figure 1A-C. PMNs within the CL were detected (red-stained cells indicating arrows) using paraffin sections stained with periodic acid - Schiff's (PAS) reagent (Figure 2A-F). On day 1-2 of the estrous cycle, high numbers of PMNs were detected within the luteal tissue (Figure $1 \mathrm{~A}$ and $2 \mathrm{~A}$ ).

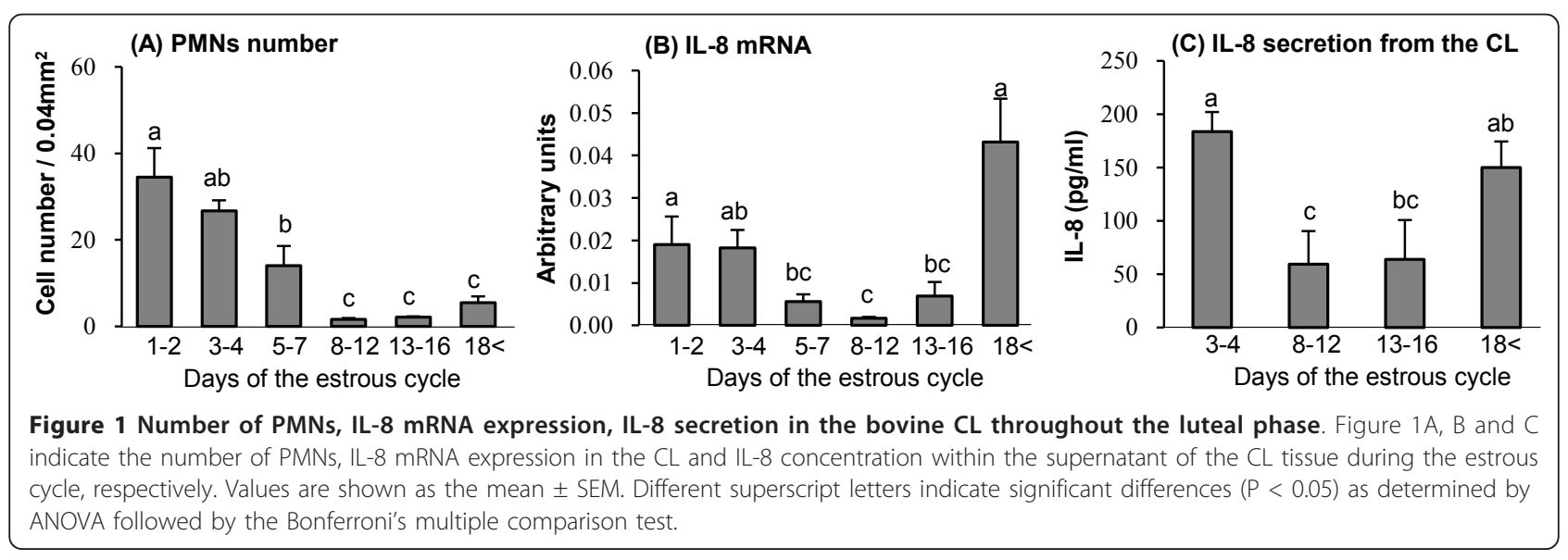




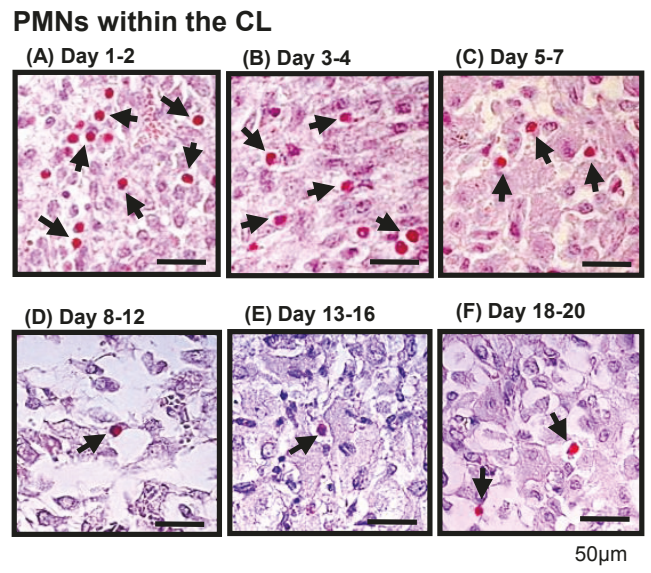

Figure 2 Distribution of PMNs in the bovine CL throughout the luteal phase. Figure $2 \mathrm{~A}-\mathrm{F}$ indicate typical images of PMNs by PAS staining in the $\mathrm{CL}$ during the estrous cycle. Black arrows indicate PMNs. PMNs were clear granule and segmented nuclear. As Figure $1 \mathrm{~A}$, on day $1-2$ and 3-4 of the estrous cycle, high numbers of PMNs were detected within the luteal tissue (Figure 2A and B). Scale bars indicate $50 \mu \mathrm{m}$

Continuously, PMNs were present in substantially higher numbers on Day 3-4 and 5-7 in the early stage of the estrous cycle (Figure $1 \mathrm{~A}, 2 \mathrm{~B}$ and $2 \mathrm{C}, \mathrm{P}<0.01$ ), and then reduced mid- (Figure $1 \mathrm{~A}$ and $2 \mathrm{D}$ ), late- (Figure 1A and $2 \mathrm{E}$ ) and luteal regression (Figure $1 \mathrm{~A}$ and $2 \mathrm{~F}$ ).

IL-8 mRNA expression was higher in the early (especially Days 1-4) and regression luteal phases (days 18 or greater) compared with mid and/or late luteal phases of the estrous cycle (Figure 1B). IL-8 concentration within the supernatant of the CL tissue is shown in Figure $1 \mathrm{C}$. Early CL had highest levels of IL-8 during the estrous cycle, and IL-8 in regressing CL was higher than in mid and late CL (Figure 1C). Also, we investigated IL-8 mRNA expression depending on the LCs, LECs and PMNs (Figure 3). PMNs were the highest expression of

\section{IL-8 mRNA in cell types}

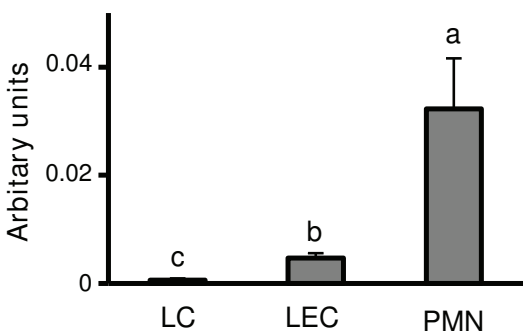

Figure 3 IL-8 mRNA expression in LCs, LECs and PMNs. Figure 3 show IL-8 mRNA expression depending on the types of cells, such as LCS, LECs and PMNs. Values are shown as the mean \pm SEM. Different superscript letters indicate significant differences $(P<0.05)$ as determined by ANOVA followed by the Bonferroni's multiple comparison test.
IL-8 mRNA, and IL-8 mRNA was expressed higher levels in LECs compared to LCs.

PMN migration by $\mathrm{CL}$ supernatant derived from the early and mid $C L$, and PMN migration by the early-phase $C L$ supernatant with or without anti-IL-8 antibody pretreatment

Based on the results of Figure 1-2, we hypothesized that PMN infiltration is dependent on a chemoattractant produced by the CL, especially IL-8. Before PMNs migration experiment, we evaluated the purity of PMNs separation from white blood cells using flow cytometry. Figure 4A indicates the plotting data of peripheral white blood cells (not separate between PMNs and pheripheral blood mononuclear cells (PBMCs)). After removing PBMCs layer using Lymphoprep, we observed clear separation of PMN population (Figure 4B) and the purity of PMNs was > 95\% and these cells resulted in nearly pure granulocyte populations as determined by flow cytometric evaluation. PMN migration by the supernatant obtained from early- and mid-phase CL cultures are shown in Figure $4 \mathrm{C}$. The data show that the supernatant obtained from the early CL significantly induced PMN migration as well as IL-8 $(50 \mathrm{ng} / \mathrm{ml}$ as a positive control) compared with control (culture medium was applied in the bottom chamber). The supernatant from the mid-phase CL could not induce PMN migration. To investigate the possible role of IL-8 as a neutrophil-specific chemoattractant in early-phase CL tissue culture supernatant, we inhibited IL-8 function using anti-IL-8 monoclonal antibody react with the bovine IL-8 (Ab; MAB1044, Millipore Corporation, Australia) and then performed a transmigration assay. Based on the PMN migration ratio in the without anti-IL-8 antibody pretreatment group (control IgG treatment), the level of PMN migration was significantly lower in the IL- 8 antibody pre-treatment group compared with the control IgG-treatment group ( $n=4$, Figure 4D).

\section{Effect of IL-8 and PMNs on the function of luteal endothelial cells}

Figure 5A-E shows the effect of IL-8 and PMNs on the function of luteal endothelial cells (LEC) in vitro. FGF2 $(10 \mathrm{ng} / \mathrm{ml})$ was used as a positive control as general angiogenic factor. In Figure 5A, the data show that IL-8 at 10 and $100 \mathrm{ng} / \mathrm{ml}$ as well as FGF2 stimulated live cell number of LECs at $48 \mathrm{~h}$ compared with control. To investigate the ability of IL-8 and PMNs for angiogenesis, LEC capillary tube formation was evaluated using matrigel and tubular formation was assessed by the length of capillary-like tube structure and the area of tubular structure as previously described [29]. The data show that IL-8 at 10 and $100 \mathrm{ng} / \mathrm{ml}$ as well as FGF2 stimulated the length of capillary-like tube structure 


\section{Flow cytometric analysis}

\section{(A) Before separation \\ (B) After separation between PMNs and PBMCs between PMNs and PBMCs}

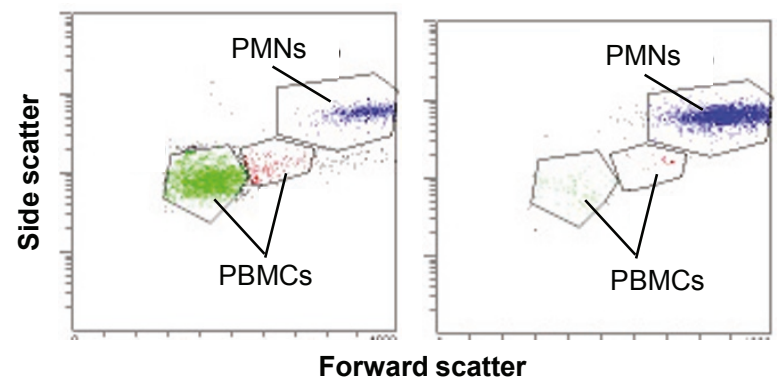

(C) PMN migration by the CL supernatant

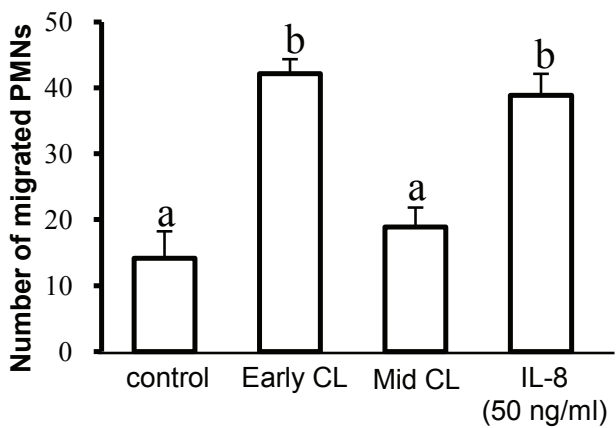

(D) Reduction rate of migrated PMNs

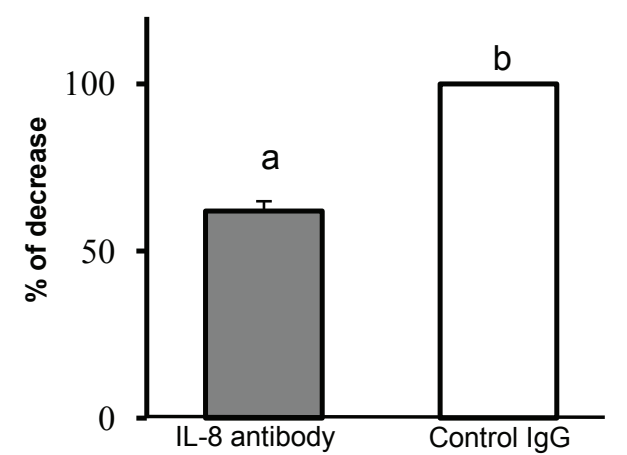

Figure 4 PMN migration by the supernatant of early and mid CL culture and PMN migration levels with or without anti-IL-8 Ab pretreatment. Before PMNs migration experiment, we evaluated the purity of PMNs separation from white blood cells using flow cytometry. Figure $4 \mathrm{~A}$ indicates the plotting data of peripheral white blood cells (not separate between PMNs and pheripheral blood mononuclear cells (PBMCs)). After removing PBMCs layer using Lymphoprep, we observed clear separation of PMN population (Figure 4B) and the purity of PMNs was $>95 \%$ and these cells resulted in nearly pure granulocyte populations as determined by flow cytometric evaluation. PMN migration by the supernatant obtained from early- and mid-phase CL cultures are shown in Figure 4C. The supernatant of the early CL significantly induced PMN migration as well as IL-8 $(50 \mathrm{ng} / \mathrm{ml}$ as a positive control) compared with control. Figure 4D indicates the reduction ratio of migrated PMNs using the supernatant of the early $\mathrm{CL}$ with anti-IL-8 monoclonal antibody or control IgG. All values are the mean $\pm \mathrm{SEM}$. Different superscript letters indicate significant differences $(P<0.05)$ as determined by ANOVA followed by the Bonferroni's multiple comparison test.

(Figure 5B) and the area of tubular structure (Figure 5C) at 8 h compared with control $(\mathrm{n}=4, \mathrm{P}<0.05)$. Typical images of tubular formation of LEC of control, IL-8 (10 and $100 \mathrm{ng} / \mathrm{ml}$ ) and FGF2 are shown in Figure 6A-D, respectively.
To investigate of PMNs for the function of LEC, PMNs from the early luteal phase were cultured to activate in the presence of $\mathrm{N}$-formyl-methionyl-leucyl-phenylalanine (fMLP; 10 and $100 \mathrm{nM}$ ) or without fMLP as control for 1 $h$ at $37^{\circ} \mathrm{C}$ as previously described [15]. After stimulation of 
(A) LEC proliferation
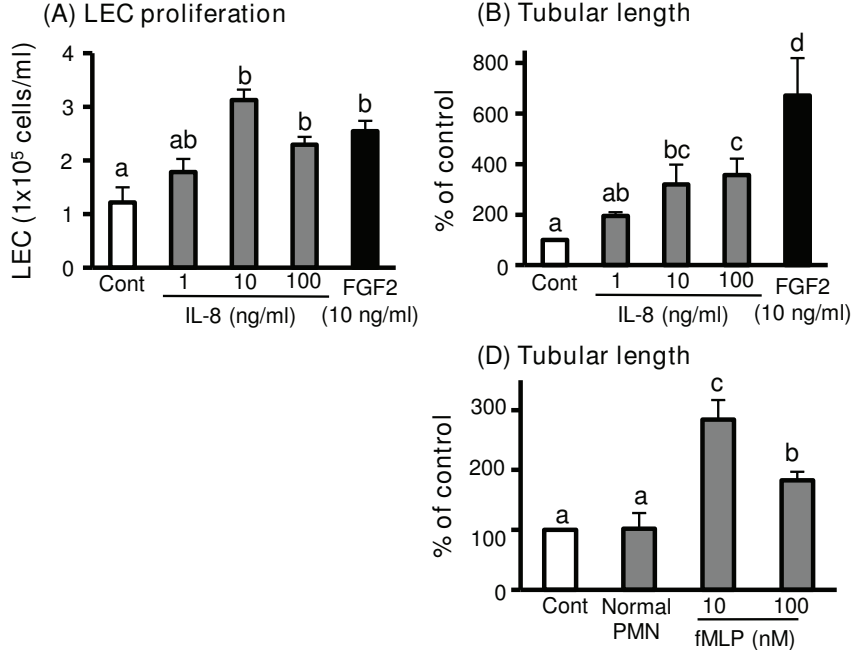

(C) Tubular area

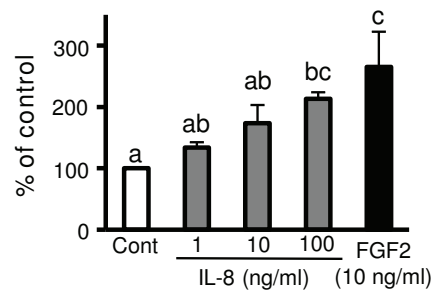

(E) Tubular area

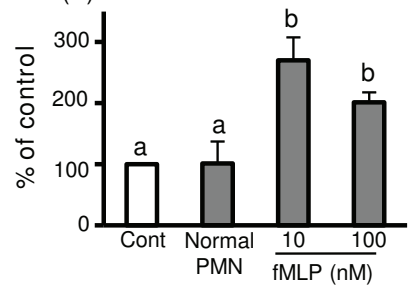

Figure 5 Effects of IL-8 and activated PMNs on live cell number and tubular formation of LEC. Figure $5 A-C$ shows the effect of IL-8 and PMNs on the function of LECs in vitro. Figure $5 A$ shows that IL-8 at 10 and $100 \mathrm{ng} / \mathrm{ml}$ as well as FGF2 stimulated live cell number of LECs. The data show that IL-8 at 10 and $100 \mathrm{ng} / \mathrm{ml}$ as well as FGF2 stimulated the length of capillary-like tube (Figure 5B), and the area of tubular structure (Figure $5 C, n=4)$. Figure $5 D$ and $E$ shows the effects of PMNs on tubular formation of LECs. PMNs from the early luteal phase were cultured to activate in the presence of fMLP (10 and $100 \mathrm{nM}$ ) or without fMLP. An in vitro matrigel assay, the supernatant of activated-PMNs stimulated sprouting of capillary-like structures of LECS $(n=4, P<0.05)$ compared with control and normal PMNs (non-activated supernatant of PMNs). Values are shown as the mean \pm SEM. Different superscript letters indicate significant differences $(P<0.05)$ as determined by ANOVA followed by the Bonferroni's multiple comparison test.

PMNs by fMLP, supernatant of activated PMNs was harvested and then used for the assessment of capillary tube formation (Figure 5D and 5E). An in vitro matrigel assay, the supernatant of activated-PMNs stimulated sprouting of capillary-like structures of LECs $(\mathrm{n}=4, \mathrm{P}<0.05)$ compared with control (culture medium alone) and normal PMNs (un-activated supernatant of PMNs). Typical images of tubular formation of LEC of control, fMLP-stimulated PMNs (10 and $100 \mathrm{nM}$ ) and normal PMNs are shown in Figure 6E-H, respectively.

\section{Discussion}

This study demonstrated the presence of PMN populations and IL-8 expression (mRNA and protein) within
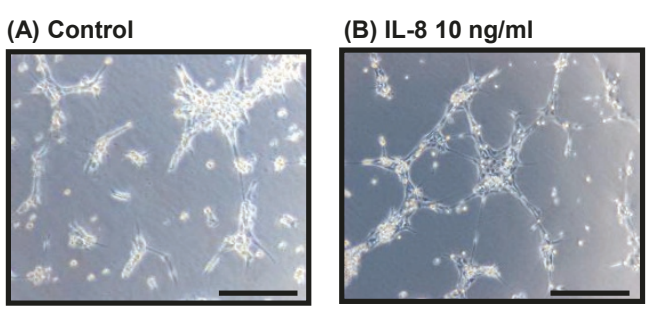

(E) Control

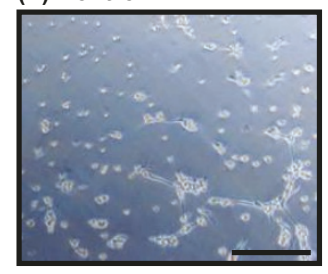

(F) Supernatant of normal PMNs

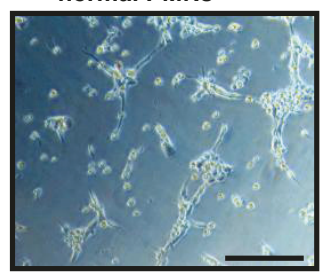

(C) IL-8 $100 \mathrm{ng} / \mathrm{ml}$

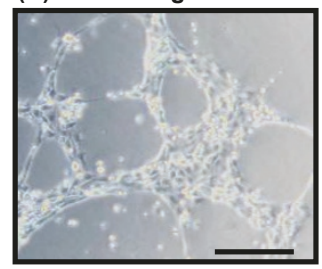

(G) Supernatant of PMNs by $10 \mathrm{nM}$ of fMLP

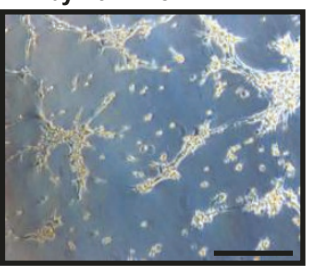

\section{(D) FGF2 $10 \mathrm{ng} / \mathrm{ml}$}

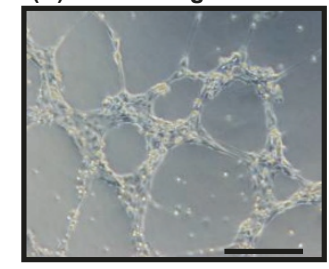

(H) Supernatant of PMNs by $100 \mathrm{nM}$ of $\mathrm{fMLP}$

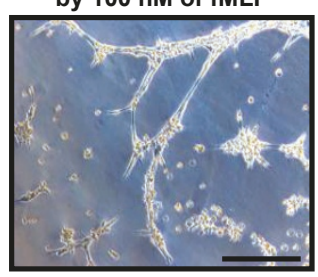

$200 \mu \mathrm{m}$

Figure 6 Image of tubular formation of LEC by IL-8 and activated PMNs. Typical images of tubular formation of LEC of control, IL-8 (10 and $100 \mathrm{ng} / \mathrm{ml}$ ), FGF2 (positive control), fMLP-stimulated PMNs (10 and $100 \mathrm{nM}$ ) and normal PMNs are shown in Figure 6A-H, respectively. Scale bars indicate $200 \mu \mathrm{m}$ 
the CL during the estrous cycle in cows. Particularly, PMNs and IL- 8 expression were predominant in the very early stage of the luteal phase. The early bovine $\mathrm{CL}$ induced PMN migration at least in part via IL-8 in vitro, and PMNs as well as IL-8 stimulated capillary-like structures of LECs in vitro. These findings suggest that PMNs and IL-8, a neutrophil-specific chemoattractant, have important roles in CL angiogenesis in cows.

The CL formation occurs by the rapidly induced terminal differentiation of granulosa and theca cells into luteal cells and promotes tissue transformation including break-down of the follicular basal lamina and migration of various cell types, such as leukocytes and endothelial cells into the granulosa layer, which eventually leads to neovascularization. In the present study, the early bovine CL, specifically days 1-4 of the estrous cycle possessed a large number of PMNs together with high levels of IL-8 expression (Figure 1). Therefore, we hypothesized that PMNs infiltrated via IL-8 in the developing CL may play a role in angiogenesis of the CL.

To investigate the role of PMNs and IL- 8 in CL development, we focused on the mechanism of PMN migration in the bovine CL. In the present study, we investigated the factors secreted from the CL to induce migration of PMNs. The early CL produced a greater quantity of IL-8, a good candidate of neutrophil-specific chemoattractant compared to the mid CL. Indeed, PMN migration was stimulated by the supernatant from the early CL but not from the mid CL, and this active PMN migration in the early CL was partially inhibited by pretreatment with anti-IL-8 antibody (Figure 4D). However, treatment of IL-8 antibody could not completely inhibited (only 40\%) the PMN migration by the supernatant of the early CL. Interestingly, as in the case of IL-8, FGF2 and VEGFA (10 and $100 \mathrm{ng} / \mathrm{ml}$ ) stimulated PMN migration in vitro (our preliminary study, data not shown), and FGF2 and VEGFA are also expressed at high levels within the developing CL. Indeed, Ancelin et al. demonstrated that VEGFA was chemotactic for neutrophils in humans and that a neutralizing with antiVEGF antibody blocked this effect [14]. FGF2 also enhanced recruitment of neutrophils in rats [33]. Therefore, we speculate that IL-8, VEGFA, and FGF2 are acting synergistically as stimulators of PMN recruitment in the early CL in cows. We have to continuously investigate about this hypothesis in future study.

To elucidate our hypothesis that PMNs and IL-8 may play a role in angiogenesis of the CL, we investigated the effects of PMNs and IL-8 on the function of LECs in vitro. Similar to FGF2 as a strong angiogenic factor, IL- 8 increased proliferation of LECs and stimulated sprouting of capillary-like structures of LECs in in vitro matrigel assay. On the other hand, it has been reported that human PMNs stimulated by $100 \mathrm{nM}$ fMLP secretes substantial amount of IL- 8 at $1 \mathrm{~h}$ after stimulation and is able to induce sprouting of capillary-like structures $[15,29]$. As referred these previous study, the supernatant of activated-PMNs by fMLP as well as FGF2 in the present study, stimulated sprouting of capillary-like structures of LECs in in vitro matrigel assay, suggesting the crucial role of PMNs-IL-8 axis in the developing CL in cows. Actually, PMNs and IL-8 can induce angiogenesis in vivo [16,21] and in vitro [15,29], suggesting that the PMNs-IL-8 duo may function not only in the induction of tissue inflammation and wound healing, but also in the regulation of angiogenesis.

Angiogenesis is a critical component of normal luteal function, and FGF2 and VEGFA are major angiogenic factors in the bovine CL [34-37]. Indeed, Robinson et al., demonstrated that in a luteal angiogenesis culture system (involves luteal cells, endothelial cells and smooth muscle cells), a physiological dose $(1 \mathrm{ng} / \mathrm{ml})$ of FGF2 and VEGFA stimulates the degree of the endothelial cell network [35]. In addition, we recently showed that treatment with FGF2 and VEGFA antibodies markedly suppressed angiogenesis in the early luteal phase of the bovine CL in vivo [37]. VEGFA stimulated the mRNA expression of IL-8 in bovine theca [38] and human endothelial cells [15]. These findings suggest that PMNs and IL-8 together with FGF2 and VEGFA actively contribute to induce angiogenesis during the early CL development.

Similarly to PMNs in the present study, macrophages and lymphocytes have been identified in the developing CL in several species [11,39-41], and have been suggested to be putative intraovarian regulators. Indeed, peripheral blood lymphocytes and macrophages indicated a luteotrophic effect as these cells stimulated $\mathrm{P}$ secretion upon co-culture with granulosa cells [42-44]. Meanwhile, Furukawa et al. revealed that platelets are novel regulators of neovascularization and luteinization during the early luteal phase in humans [45]. An increased number of platelets localized to extravascular sites among luteinizing granulosa cells after ovulation and gradually decreased toward the mid luteal phase [45], that are similar to the PMN profile observed in the present study. Moreover, platelets stimulated P secretion in luteinizing granulosa cells and endothelial cell migration [45]. Taken together, these findings suggest that immune and blood cells are active components in CL development including angiogenesis, luteinization and $\mathrm{P}$ secretion.

\section{Conclusion}

This study showed that PMNs migrate into the early CL partially due to its major chemoattractant IL- 8 produced at high levels in the CL, and they are most likely to be involved in the regulation of angiogenesis. Thus, 
PMNs are novel regulators of early CL development in the cow.

\author{
Acknowledgements \\ The authors thank Dr. K Okuda, Okayama University, Japan, for the P \\ antiserum. This study was supported by a Grant-in-Aid for Scientific Research \\ of the Japan Society for the Promotion of Science (JSPS) and the Global \\ COE Program, Ministry of Education, Culture, Sports, Science and \\ Technology, Japan. This manuscript was reviewed by a professional service \\ (KUSR002, Editage Cactus Communications Inc., Trevose, PA, USA) prior to \\ submission.

\section{Author details} \\ ${ }^{1}$ Graduate School of Animal and Food Hygiene, Obihiro University of \\ Agriculture and Veterinary Medicine, Obihiro 080-8555, Japan. ${ }^{2}$ Institute of \\ Immunology, University of Veterinary Medicine Hannover, 30173 Hannover, \\ Germany.
}

\section{Authors' contributions}

SJ participated carried out all experiments and drafted the manuscript. KS participated in the design of the study, experiments of in vitro angiogenesis and drafted the manuscript. AN and AK collected the materials, and helped to immunohistochemistry and in vitro cell culture experiments. HJS and TS helped the design of the study and instructed technique of the experiments. AM supervised the study and helped to draft the manuscript. All authors read and approved the final manuscript.

\section{Competing interests}

The authors declare that they have no competing interests.

Received: 28 April 2011 Accepted: 8 June 2011 Published: 8 June 2011

\section{References}

1. Mann GE, Lamming GE, Robinson RS, Wathes DC: The regulation of interferon-tau production and uterine hormone receptors during early pregnancy. J Reprod Fertil Suppl 1999, 54:317-328.

2. Gospodarowicz D, Cheng J, Lui GM, Baird A, Esch F, Bohlen P: Corpus luteum angiogenic factor is related to fibroblast growth factor. Endocrinology 1985, 117(6):2383-2391.

3. Berisha B, Schams D, Kosmann M, Amselgruber W, Einspanier R: Expression and localisation of vascular endothelial growth factor and basic fibroblast growth factor during the final growth of bovine ovarian follicles. J Endocrinol 2000, 167(3):371-382.

4. Short RE, Staigmiller RB, Bellows RA, Ford SP: Endocrine responses in cows fed Ponderosa pine needles and the effects of stress, corpus luteum regression, progestin, and ketoprofen. J Anim Sci 1995, 73(1):198-205.

5. Murdoch WJ, Colgin DC, Ellis JA: Role of tumor necrosis factor-alpha in the ovulatory mechanism of ewes. J Anim Sci 1997, 75(6):1601-1605.

6. Hurwitz A, Payne DW, Packman JN, Andreani CL, Resnick CE, Hernandez ER, Adashi EY: Cytokine-mediated regulation of ovarian function: interleukin1 inhibits gonadotropin-induced androgen biosynthesis. Endocrinology 1991, 129(3):1250-1256.

7. Chang RJ, Gougeon A, Erickson GF: Evidence for a neutrophil-interleukin-8 system in human folliculogenesis. Am J Obstet Gynecol 1998, 178(4):650-657.

8. Yoshino O, Osuga Y, Koga K, Hirota Y, Yano T, Tsutsumi O, Fujimoto A, Kugu K, Momoeda M, Fujiwara T, et al: Upregulation of interleukin-8 by hypoxia in human ovaries. Am J Reprod Immunol 2003, 50(4):286-290.

9. Brannstrom M, Norman RJ: Involvement of leukocytes and cytokines in the ovulatory process and corpus luteum function. Hum Reprod 1993, 8(10):1762-1775

10. Brannstrom M, Bonello N, Norman RJ, Robertson SA: Reduction of ovulation rate in the rat by administration of a neutrophil-depleting monoclonal antibody. J Reprod Immunol 1995, 29(3):265-270.

11. Brannstrom M, Giesecke L, Moore IC, van den Heuvel CJ, Robertson SA: Leukocyte subpopulations in the rat corpus luteum during pregnancy and pseudopregnancy. Biol Reprod 1994, 50(5):1161-1167.

12. Reibiger I, Spanel-Borowski K: Difference in localization of eosinophils and mast cells in the bovine ovary. J Reprod Fertil 2000, 118(2):243-249.
13. Aust G, Simchen C, Heider U, Hmeidan FA, Blumenauer V, SpanelBorowski K: Eosinophils in the human corpus luteum: the role of RANTES and eotaxin in eosinophil attraction into periovulatory structures. $\mathrm{Mol}$ Hum Reprod 2000, 6(12):1085-1091.

14. Ancelin M, Chollet-Martin S, Herve MA, Legrand C, El Benna J, PerrotApplanat M: Vascular endothelial growth factor VEGF189 induces human neutrophil chemotaxis in extravascular tissue via an autocrine amplification mechanism. Lab Invest 2004, 84(4):502-512.

15. Schruefer R, Lutze N, Schymeinsky J, Walzog B: Human neutrophils promote angiogenesis by a paracrine feedforward mechanism involving endothelial interleukin-8. Am J Physiol Heart Circ Physiol 2005, 288(3): H1186-1192.

16. Koch AE, Polverini PJ, Kunkel SL, Harlow LA, DiPietro LA, Elner VM, Elner SG, Strieter RM: Interleukin-8 as a macrophage-derived mediator of angiogenesis. Science 1992, 258(5089):1798-1801.

17. Li A, Varney ML, Valasek J, Godfrey M, Dave BJ, Singh RK: Autocrine role of interleukin-8 in induction of endothelial cell proliferation, survival, migration and MMP-2 production and angiogenesis. Angiogenesis 2005, 8(1):63-71

18. Arici A, Oral E, Bukulmez O, Buradagunta S, Engin O, Olive DL: Interleukin-8 expression and modulation in human preovulatory follicles and ovarian cells. Endocrinology 1996, 137(9):3762-3769.

19. Polec A, Tanbo T, Fedorcsak P: Cellular interaction regulates interleukin-8 secretion by granulosa-lutein cells and monocytes/macrophages. Am J Reprod Immunol 2009, 61(1):85-94.

20. Belayet HM, Kanayama N, Khatun S, Asahina T, Okada Y, Kitamura K, Kobayashi T, Terao T: Pharmacologic doses of interleukin 8 suppositories induce follicular maturation in rabbits. Cytokine 2000, 12(4):361-367.

21. Goto J, Suganuma N, Takata K, Kitamura K, Asahina T, Kobayashi H, Muranaka Y, Furuhashi M, Kanayama N: Morphological analyses of interleukin-8 effects on rat ovarian follicles at ovulation and luteinization in vivo. Cytokine 2002, 20(4):168-173.

22. Ujioka T, Matsukawa A, Tanaka N, Matsuura K, Yoshinaga M, Okamura H: Interleukin-8 as an essential factor in the human chorionic gonadotropin-induced rabbit ovulatory process: interleukin-8 induces neutrophil accumulation and activation in ovulation. Biol Reprod 1998, 58(2):526-530.

23. Miyamoto A, Schams D: Oxytocin stimulates progesterone release from microdialyzed bovine corpus luteum in vitro. Biol Reprod 1991, 44(6):1163-1170.

24. Miyamoto A, Okuda K, Schweigert FJ, Schams D: Effects of basic fibroblast growth factor, transforming growth factor-beta and nerve growth factor on the secretory function of the bovine corpus luteum in vitro. $J$ Endocrinol 1992, 135(1):103-114.

25. Klipper E, Gilboa T, Levy N, Kisliouk T, Spanel-Borowski K, Meidan R: Characterization of endothelin-1 and nitric oxide generating systems in corpus luteum-derived endothelial cells. Reproduction 2004, 128(4):463-473.

26. Spanel-Borowski K: Diversity of ultrastructure in different phenotypes of cultured microvessel endothelial cells isolated from bovine corpus luteum. Cell Tissue Res 1991, 266(1):37-49.

27. Zerbe H, Schneider N, Leibold W, Wensing T, Kruip TA, Schuberth HJ: Altered functional and immunophenotypical properties of neutrophilic granulocytes in postpartum cows associated with fatty liver. Theriogenology 2000, 54(5):771-786.

28. Mehrzad J, Klein G, Kamphues J, Wolf P, Grabowski N, Schuberth HJ: In vitro effects of very low levels of aflatoxin $B(1)$ on free radicals production and bactericidal activity of bovine blood neutrophils. Vet Immunol Immunopathol 2011, 141(1-2):16-25.

29. Yasuda M, Shimizu S, Tokuyama S, Watanabe T, Kiuchi Y, Yamamoto T: A novel effect of polymorphonuclear leukocytes in the facilitation of angiogenesis. Life Sci 2000, 66(21):2113-2121.

30. Al-Zi'abi MO, Fraser HM, Watson ED: Cell death during natural and induced luteal regression in mares. Reproduction 2002, 123(1):67-77.

31. Chomczynski P, Sacchi N: Single-step method of RNA isolation by acid guanidinium thiocyanate-phenol-chloroform extraction. Anal Biochem 1987, 162(1):156-159

32. Watanabe S, Shirasuna K, Matsui M, Yamamoto D, Berisha B, Schams D, Miyamoto A: Effect of intraluteal injection of endothelin type $A$ receptor antagonist on PGF2alpha-induced luteolysis in the cow. $J$ Reprod Dev 2006, 52(4):551-559. 
33. Zittermann SI, Issekutz AC: Endothelial growth factors VEGF and bFGF differentially enhance monocyte and neutrophil recruitment to inflammation. J Leukoc Biol 2006, 80(2):247-257.

34. Schams D, Berisha B: Regulation of corpus luteum function in cattle-an overview. Reprod Domest Anim 2004, 39(4):241-251.

35. Robinson RS, Hammond AJ, Mann GE, Hunter MG: A novel physiological culture system that mimics luteal angiogenesis. Reproduction 2008, 135(3):405-413.

36. Robinson RS, Woad KJ, Hammond AJ, Laird M, Hunter MG, Mann GE: Angiogenesis and vascular function in the ovary. Reproduction 2009, 138(6):869-881.

37. Yamashita H, Kamada D, Shirasuna K, Matsui M, Shimizu T, Kida K, Berisha B, Schams D, Miyamoto A: Effect of local neutralization of basic fibroblast growth factor or vascular endothelial growth factor by a specific antibody on the development of the corpus luteum in the cow. Mol Reprod Dev 2008, 75:1449-1456

38. Murayama C, Kaji A, Miyauchi K, Matsui M, Miyamoto A, Shimizu T: Effect of VEGF (vascular endothelial growth factor) on expression of IL-8 (interleukin-8), IL-1beta and their receptors in bovine theca cells. Cell Biol Int 2010, 34(5):531-536.

39. Adashi EY: The potential relevance of cytokines to ovarian physiology: the emerging role of resident ovarian cells of the white blood cell series. Endocr Rev 1990, 11(3):454-464.

40. Standaert FE, Zamora CS, Chew BP: Quantitative and qualitative changes in blood leukocytes in the porcine ovary. Am J Reprod Immunol 1991, 25(4):163-168.

41. Penny LA, Armstrong D, Bramley TA, Webb R, Collins RA, Watson ED: Immune cells and cytokine production in the bovine corpus luteum throughout the oestrous cycle and after induced luteolysis. J Reprod Fertil 1999, 115(1):87-96

42. Emi N, Kanzaki H, Yoshida M, Takakura K, Kariya M, Okamoto N, Imai K, Mori T: Lymphocytes stimulate progesterone production by cultured human granulosa luteal cells. Am J Obstet Gynecol 1991, 165(5 Pt 1):1469-1474.

43. Halme J, Hammond MG, Syrop CH, Talbert LM: Peritoneal macrophages modulate human granulosa-luteal cell progesterone production. J Clin Endocrinol Metab 1985, 61(5):912-916.

44. Hashii K, Fujiwara H, Yoshioka S, Kataoka N, Yamada S, Hirano T, Mori T, Fujii S, Maeda M: Peripheral blood mononuclear cells stimulate progesterone production by luteal cells derived from pregnant and nonpregnant women: possible involvement of interleukin-4 and interleukin10 in corpus luteum function and differentiation. Hum Reprod 1998, 13(10):2738-2744

45. Furukawa K, Fujiwara H, Sato Y, Zeng BX, Fujii H, Yoshioka S, Nishi E, Nishio T: Platelets are novel regulators of neovascularization and luteinization during human corpus luteum formation. Endocrinology 2007, 148(7):3056-3064.

doi:10.1186/1477-7827-9-79

Cite this article as: Jiemtaweeboon et al: Evidence that

polymorphonuclear neutrophils infiltrate into the developing corpus

luteum and promote angiogenesis with interleukin-8 in the cow.

Reproductive Biology and Endocrinology 2011 9:79.

\section{Submit your next manuscript to BioMed Central and take full advantage of:}

- Convenient online submission

- Thorough peer review

- No space constraints or color figure charges

- Immediate publication on acceptance

- Inclusion in PubMed, CAS, Scopus and Google Scholar

- Research which is freely available for redistribution

Submit your manuscript at www.biomedcentral.com/submit
Ciomed Central 